\title{
Anti-Phospholipase $A_{2}$ Receptor Antibodies and the Pathogenesis of Membranous Nephropathy
}

\author{
Pierre Ronco ${ }^{a-c}$ Hanna Debiec ${ }^{a, b}$ \\ a Sorbonne Universités, UPMC Univ Paris 06, UMR-S 1155, 'b INSERM, UMR-S 1155, and ' AP-HP, Nephrology and \\ Dialysis, Tenon Hospital, Paris, France
}

\section{Key Words}

Heymann nephritis · Membranous nephropathy ·

Phospholipase $A_{2}$ receptor

\begin{abstract}
Since the early 2000s, considerable advances have been achieved in the understanding of molecular pathomechanisms of human membranous nephropathy (MN), inspired by studies of Heymann nephritis, a faithful experimental model. These studies led to the identification of neutral endopeptidase, the type-M phospholipase $A_{2}$ receptor $\left(P L A_{2} R\right)$, and cationic bovine serum albumin as target antigens of circulating and deposited antibodies in neonatal alloimmune, adult 'idiopathic', and early childhood MN, respectively. A genome-wide association study further showed a highly significant association of the $P L A_{2} R 1$ and the HLA-DQA1 loci with idiopathic $M N$ in patients of white ancestry. The time has come to revisit the spectrum of MN based on the newly identified antigen-antibody systems which should be considered as molecular signatures of the disease, challenging the uniform histological definition. Although some uncertainties remain as to the pathogenic effects of anti-PLA $R$ antibodies because of the lack of an appropriate experimental model, the value of these antibodies as biomarkers for diagnosis and disease activity is increasingly being recognized. It
\end{abstract}

is not exaggerated to state that they have induced a paradigm shift in the monitoring of patients with $\mathrm{MN}$, thus opening a new era of personalized medicine.

(c) 2014 S. Karger AG, Basel

In the past 10 years, substantial advances have occurred in the understanding of the molecular pathomechanisms of human membranous nephropathy (MN). These advances were inspired by studies of experimental models of MN such as Heymann nephritis [1] and MN induced by cationic bovine serum albumin (BSA) [2]. Studies of Heymann nephritis led to the concept that a podocyte antigen - megalin - could serve as a target of circulating antibodies leading to the in situ formation of immune complexes [3], while cationic BSA-related MN first illustrated the case of 'planted' antigen. In humans, progress started in 2002 with the identification by our group of neutral endopeptidase (also known as neprilysin) as the target antigen in a rare subset of patients with alloimmune antenatal MN $[4,5]$. This finding provided

Biologic Treatment in Glomerular Disease D. Jayne, Cambridge

V. Tesar, Prague

\section{KARGER}

E-Mail karger@karger.com

www.karger.com/nec
(C) 2014 S. Karger AG, Basel

$1660-2110 / 14 / 1284-0232 \$ 39.50 / 0$
Pierre Ronco

INSERM Unit 1155, Hôpital Tenon

4 rue de la Chine

FR-75020 Paris (France)

E-Mail pierre.ronco@upmc.fr 
the proof of concept that a podocyte antigen could be involved in human $\mathrm{MN}$, as is the case for megalin in the rat, and laid the foundation for the identification of M-type phospholipase $A_{2}$ receptor $\left(\mathrm{PLA}_{2} \mathrm{R}\right)$, which was the first podocyte autoantigen shown to be associated with idiopathic $\mathrm{MN}$ in humans [6]. Genome-wide association studies further showed that single nucleotide polymorphisms in the $P L A_{2} R 1$ gene were strongly associated with idiopathic $\mathrm{MN}$ [7], which again pointed to the implication of this antigen using an unbiased genetic approach. In addition to podocyte antigens, exogenous antigens such as cationic BSA have also been implicated in some patients with early childhood MN [8]. All of these findings have opened up a new era for the diagnosis and monitoring of $\mathrm{MN}$ from early infancy to adulthood.

In this chapter, we will focus on anti-PLA ${ }_{2} \mathrm{R}$ antibodies, discuss their pathogenicity and show how they have induced a paradigm shift in diagnosis, monitoring and even therapy in patients with primary, so-called idiopathic, $\mathrm{MN}$.

\section{First Characterization of Anti-PLA ${ }_{2} \mathrm{R}$ Antibodies in 2009, 50 Years after the Description of Heymann Nephritis}

The use of glycoprotein-enriched glomerular extracts from human kidneys as a source of antigens, and of nonreducing conditions for Western blots, enabled the identification of a $185-\mathrm{kD}$ a protein band that was detected in about $70 \%$ of patients with idiopathic MN, but not in those with secondary $\mathrm{MN}$ and in controls [6]. Reactivity to this protein persisted after $\mathrm{N}$-deglycosylation, but disappeared after reduction of the disulfide bonds. The type-M PLA ${ }_{2} \mathrm{R}$ was identified by mass spectrometry analysis of the reactive band. Furthermore, sera from patients with $\mathrm{MN}$ immunoprecipitated $\mathrm{PLA}_{2} \mathrm{R}$ from glomerular extracts. Although anti-PLA ${ }_{2} \mathrm{R}$ reactivity was mostly carried by $\operatorname{IgG} 4$, other subclasses were also involved, albeit to a lesser extent.

$\mathrm{PLA}_{2} \mathrm{R}$ was detected in normal human glomeruli, apparently in podocytes [6]. PLA 2 R and IgG4 were found to be colocalized within the subepithelial immune deposits in patients with idiopathic MN. Furthermore, IgG that was eluted from biopsy specimens from these patients reacted with $\mathrm{PLA}_{2} \mathrm{R}$, whereas IgG eluted from biopsy specimens from patients with lupus MN or IgA nephropathy did not. These data suggest that, like Heymann nephritis and alloimmune neonatal MN, autoimmune idiopathic $\mathrm{MN}$ involves in situ formation of subepithelial deposits through binding of circulating anti-PLA ${ }_{2} \mathrm{R}$ autoantibod-

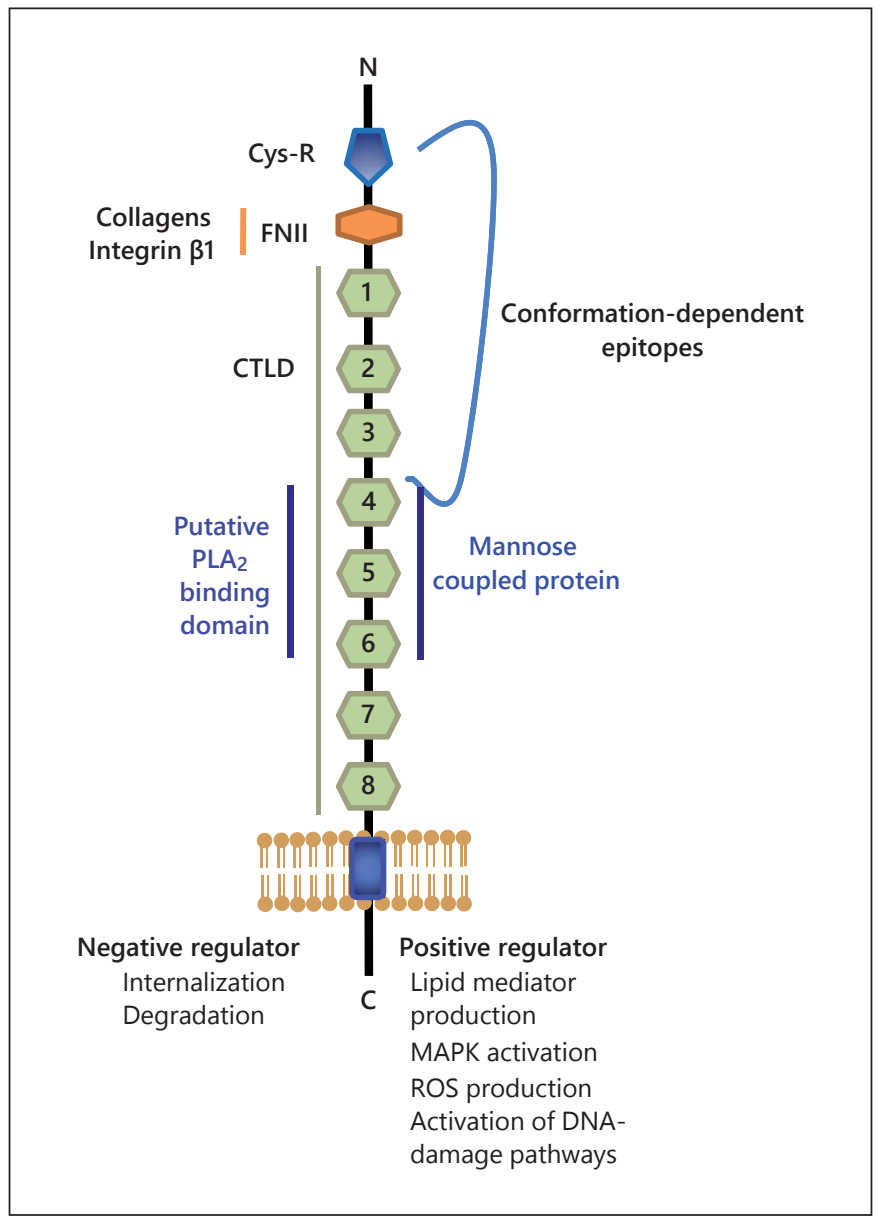

Fig. 1. Structural and functional properties of $P L A_{2} R$. This receptor is a type I transmembrane glycoprotein composed of a large extracellular portion that consists of an N-terminal cysteine-rich region, a fibronectin-like type II domain (FNII), a tandem repeat of 8 C-type lectin domains (CTLD), a transmembrane domain and a short intracellular C-terminal domain. Known interactions and domains involved are indicated. $\mathrm{PLA}_{2} \mathrm{R}$ can function as a positive regulator of $\mathrm{PLA}_{2}$ by inducing a variety of biological responses, or as a negative regulator through rapid internalization and degradation of $\mathrm{PLA}_{2}$. The blue loop shows that in the bent configuration, the $\mathrm{N}$ terminal domain folds back to interact with C-type lectin-like domains.

ies to podocyte $\mathrm{PLA}_{2} \mathrm{R}$, although this scenario is challenged by the very low level of expression of $\mathrm{PLA}_{2} \mathrm{R}$ in normal podocytes $[9,10]$.

$\mathrm{PLA}_{2} \mathrm{R}$ is a type- 1 transmembrane receptor for secretory phospholipase $\mathrm{A}_{2}$ (fig. 1), a member of the mannose receptor family, which also includes the cation-dependent mannose-6-phosphate receptor, the C-type mannose receptor 2, the dendritic cell receptor DEC-205 and the avian yolk sac IgGY receptor FcRY. Several common features are shared by members of this family [11]. First, 
all members are recycled between the plasma membrane and the endosomal machinery, leading to internalization of extracellular ligands. Second, they can present with at least two configurations: an extended confirmation with the $\mathrm{N}$-terminal cysteine-rich domain pointing outwards from the cell surface, or a bent confirmation where the $\mathrm{N}$-terminal domain folds back to interact with C-type lectin-like domains at the middle of the structure, thus affecting ligand binding and oligomerization [12]. This is especially important because the target epitope for circulating antibodies might be accessible in only one of these two configurations. Putative linear epitopes have been identified with the use of a high-throughput capture immunoassay [13]. Further work on identification and modeling of pathogenic $\mathrm{PLA}_{2} \mathrm{R}$ epitopes is ongoing in several laboratories.

\section{Predisposing Gene Variants for 'Idiopathic' MN (2011): Unbiased Confirmation of the Role of $P_{L A} R$}

The influence of genetic factors is well established both in rats and mice as well as in European Caucasoids who show a strong association of MN with the HLA-B8DR3 haplotype and other HLA class II immune response genes [14]. Genome-wide association studies have described significant associations of the 6p21 HLA-DQA1 and 2q24 $P L A_{2} R 1$ loci with idiopathic $\mathrm{MN}$ in patients of white ancestry [7]. Interestingly, carrying the risk alleles of the two genes had an additive effect. Patients with all four risk alleles had an odds ratio of about 80 for the disease compared with individuals who had only the protective alleles. These data were confirmed in ethnically distant populations from Europe and Asia [14]. The finding of common predisposing variants of $P L A_{2} R 1$ conserved across these populations and the observation that anti$\mathrm{PLA}_{2} \mathrm{R}$ antibodies were detected in $73 \%$ of the patients with the high-risk variants but absent in all carriers of protective genotypes [15] support the role of $\mathrm{PLA}_{2} \mathrm{R}$ as a major target autoantigen.

Because of the strong association of $P L A_{2} R 1$ single nucleotide polymorphisms with MN in Caucasians, we hypothesized that rare gene variants of the coding sequence could induce an unusual conformation of the antigen/ epitopes, which in turn might trigger autoimmunity. By sequencing the exons and contiguous splice sites in 95 Caucasian patients with idiopathic MN, we found only nine rare variants including two new variants in the whole patients' cohort and only four rare variants in a subset of 60 patients with $\mathrm{PLA}_{2} \mathrm{R}$-related MN [16]. These results exclude a straightforward 'conformeropathy'. Alternative explanations include rare variants in the noncoding regulatory regions which might increase the level of expression of $\mathrm{PLA}_{2} \mathrm{R}$, and/or epigenetic events of infectious or toxic origin which might modify routing and expression level of $\mathrm{PLA}_{2} \mathrm{R}$ in podocytes and other cells as well. Autoimmunity most likely results from a combination of those variants and events with predisposing immune response gene variants in the HLAD locus encoding specific HLA class II molecules which would present $\mathrm{PLA}_{2} \mathrm{R}$ pathogenic epitopes to the host immune system. Idiopathic MN represents a paradigmatic model of autoimmunity where the currently available tools will hopefully enable us to dissect the genetic bases of the triggering events as well as the mechanisms controlling disease outcome.

\section{Are Anti-PLA 2 R Antibodies Pathogenic?}

Transfer experiments to confirm the pathogenic effects of anti-PLA ${ }_{2} \mathrm{R}$ antibody have been hampered by an apparent lack of expression of $\mathrm{PLA}_{2} \mathrm{R}$ in rodent glomeruli. Furthermore, experimental models based on overexpressing $\mathrm{PLA}_{2} \mathrm{R}$ in mouse podocytes have thus far failed. However, several lines of evidence suggest that anti$\mathrm{PLA}_{2} \mathrm{R}$ antibodies are pathogenic. The first is the recurrence of $\mathrm{MN}$ in kidney transplant recipients with circulating anti-PLA ${ }_{2} \mathrm{R}$ antibodies sometimes only a few days after transplantation $[17,18]$, although some patients with high titers of anti-PLA ${ }_{2} \mathrm{R}$ antibodies at transplantation will not recur [19]. The recurrence of $\mathrm{MN}$ in a kidney transplant recipient caused by a monoclonal IgG3 kappa targeting the $\mathrm{PLA}_{2}$ receptor provides additional clues to the pathogenic effects of anti-PLA ${ }_{2} \mathrm{R}$ antibodies [20]. Second, there is accumulating evidence of a tight correlation between anti-PLA ${ }_{2} \mathrm{R}$ antibodies and disease activity, remission and relapse, although there are a few outliers that will require further investigation. Even more, the renal outcome of patients treated with rituximab can be independently predicted by the level of residual antibodies after 6 months [Ruggenenti et al., unpubl. data].

\section{PLA 2 R Antibodies - Less than 4 Years from Description to Clinical Application: A Success of High-Speed Translational Research}

Irrespective of the role of $\mathrm{PLA}_{2} \mathrm{R}$ in the pathogenesis of $\mathrm{MN}$, anti-PLA ${ }_{2} \mathrm{R}$ antibodies appear to be a very good biomarkers for this disease. Assays of circulating anti- 


\section{Serological tests}

Indirect immunofluorescence test

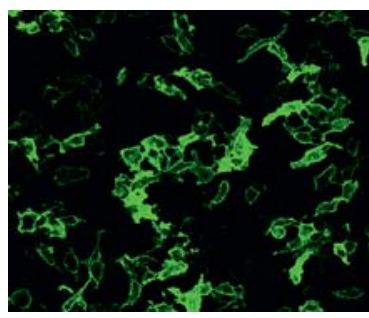

HEK293 cells transfected with PLA ${ }_{2} R$ cDNA

ELISA-PLA $A_{2}$

rhPLA $A_{2} R$-coated plates

Tissue staining for the $\mathrm{PLA}_{2} \mathrm{R}$ antigen Atlas antibodies

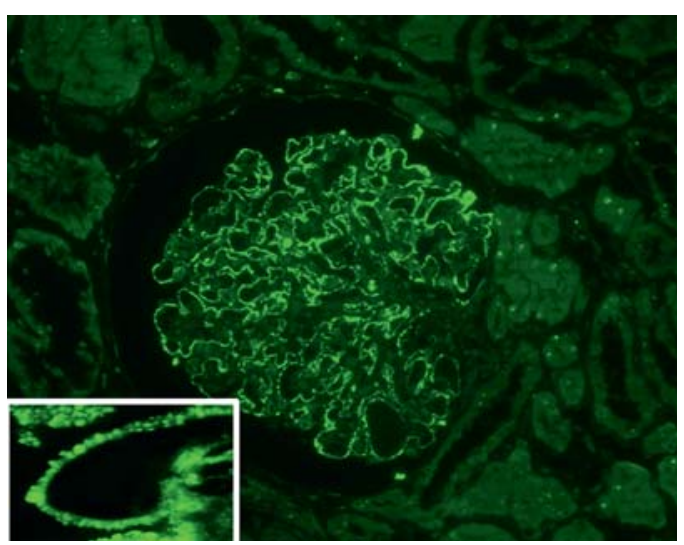

Fig. 2. Diagnostic tests. Serological assays of circulating anti$\mathrm{PLA}_{2} \mathrm{R}$ antibodies by indirect immunofluorescence and ELISA are now commercially available. Polyclonal and monoclonal anti$\mathrm{PLA}_{2} \mathrm{R}$ antibodies used for the detection of $\mathrm{PLA}_{2} \mathrm{R}$ antigen in glomerular deposits in paraffin-embedded biopsy specimens are also commercially available.

$\mathrm{PLA}_{2} \mathrm{R}$ antibodies based on immunofluorescence of $P L A_{2} R 1$ transfected cells and on ELISA are now commercially available (fig. 2). The US Food and Drug Administration recently approved the commercial sale of these assays, and immunofluorescence assays have been available in Europe for more than 3 years. The specificity of anti-PLA 2 R for MN is close to $100 \%$. Patients with nephrotic syndrome from other causes or healthy individuals do not have detectable levels of anti-PLA ${ }_{2} \mathrm{R}$ antibodies. The specificity is such that in elderly patients, in those with poor clinical condition or those with life-threatening complications from nephrotic syndrome such as lung emboli, kidney biopsy can be postponed or even not per-

Anti-PLA 2 R Antibodies and the

Pathogenesis of $\mathrm{MN}$ formed. The sensitivity of the test for idiopathic MN has been around $70-80 \%$ in all of the studied populations so far. However, a fraction of the antibody-negative patients might have a secondary cause undiagnosed at the time of kidney biopsy.

A low prevalence of anti-PLA ${ }_{2} \mathrm{R}$ antibodies was observed in secondary forms of $\mathrm{MN}$ associated with systemic lupus erythematosus, infectious disease, drug intoxication, graft-versus-host disease and malignancy, although in those cases coincidental occurrence of the $\mathrm{PLA}_{2} \mathrm{R}$-related $\mathrm{MN}$ and underlying disorder cannot be excluded [14]. There may be exceptions, and indeed patients with MN associated with active sarcoidosis or replicating hepatitis $B$ appear to have a high prevalence of $\mathrm{PLA}_{2} \mathrm{R}$-related disease, which suggests that the immunologic setting of sarcoidosis and hepatitis B might trigger or enhance immunization against $\mathrm{PLA}_{2} \mathrm{R}$ [21-23]. Because therapeutic strategies are different for patients with idiopathic and secondary $\mathrm{MN}$, discriminating between these two groups of patients is of utmost clinical importance.

Detection of $\mathrm{PLA}_{2} \mathrm{R}$ antigen in glomerular immune deposits is even more sensitive than that of anti-PLA ${ }_{2} R$ antibodies since this antigen can be detected in antibody-negative patients $[9,23]$, which could be explained by rapid clearance of circulating antibodies, immunological remission or delayed biopsy after disease onset. This test enables the retrospective diagnosis of $\mathrm{MN}$ in archival, paraffin-embedded biopsy specimens, which is crucial for the monitoring of patients who will benefit from a kidney graft. Its positivity also is a strong clue to primary $\mathrm{MN}[10,22]$. Conversely, circulating antibodies are not always associated with deposits of $\mathrm{PLA}_{2} \mathrm{R}$ antigen, which suggests that not all antibodies to $\mathrm{PLA}_{2} \mathrm{R}$ are pathogenic [9]. Combined assessment of circulating anti-PLA ${ }_{2} \mathrm{R}$ antibodies and PLA $\mathrm{R}$ antigen in biopsy specimens might help to better select the patients for appropriate therapy.

Kidney biopsies should also be analyzed for IgG subclass distribution, which varies according to underlying disease. IgG4 is the major deposited subclass in idiopathic $\mathrm{MN}$, where it is associated with variable amounts of IgG1, IgG2 or IgG3. In contrast, in systemic lupus erythematosus and malignancy-related MN, IgG1 and IgG2 are usually the prevailing subclasses, with low or undetectable amounts of IgG4 [14]. The absence of IgG4 in early stages of MN might be a strong predictor of later occurrence of a malignancy [24].

Several studies have indicated that anti- $\mathrm{PLA}_{2} \mathrm{R}$ antibodies are correlated with urinary protein excretion and disease activity since they usually disappear during a 
Fig. 3. Time-course of anti-PLA ${ }_{2} \mathrm{R}$ antibodies and proteinuria. The figure shows the temporal relationship between proteinuria (clinical disease) and circulating anti$\mathrm{PLA}_{2} \mathrm{R}$ antibodies (immunological disease). Note that in most patients, anti$\mathrm{PLA}_{2} \mathrm{R}$ antibodies precede clinical disease activity and relapse. The time course of antibody titers predicts response to therapy, and consequently the risk of deterioration of renal function.

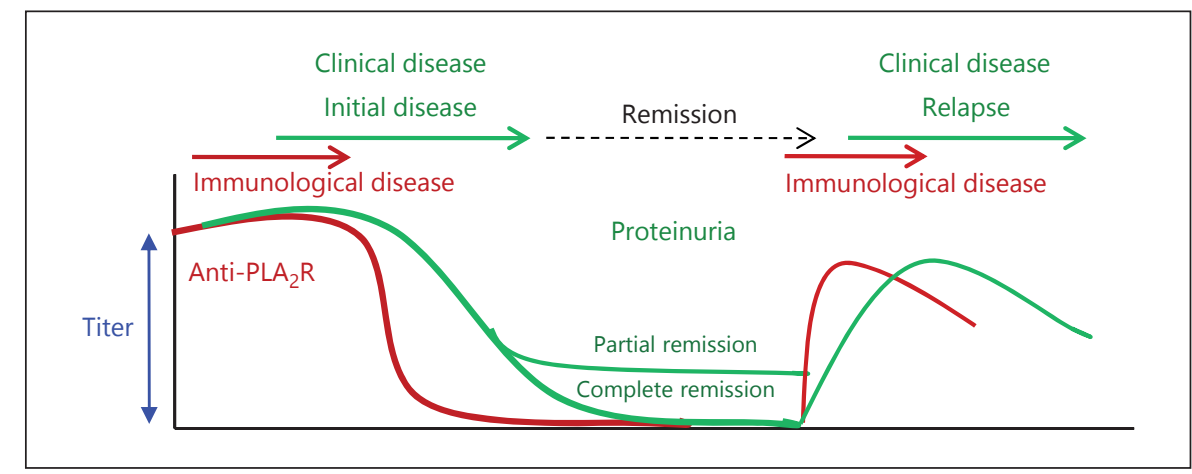

spontaneous or treatment-induced remission and reappear at relapse [6, 25-27], although there are outliers. Anti-PLA ${ }_{2} \mathrm{R}$ antibodies are also prognostic markers because a high level of these antibodies is associated with a lower chance of spontaneous [26] or immunosuppressive therapy-induced [28] remission, with a lower response rate to rituximab [Ruggenenti et al., unpubl. data] and a higher risk of deterioration of renal function [29] (fig. 3).

Quantification of anti-PLA $\mathrm{P}_{2} \mathrm{R}$ antibodies will most likely become an invaluable tool for the monitoring of disease immunological activity and the titration of immunosuppressive treatments. Antibodies disappear before proteinuria in patients treated with rituximab [25, Ruggenenti unpubl. data], which leads one to consider withdrawal of immunosuppressive treatment at the time of immunological remission before renal remission is achieved. The time lag between immunological and renal remission most likely corresponds to the time required for restoration of the glomerular capillary wall. Anti$\mathrm{PLA}_{2} \mathrm{R}$ antibody levels at the end of therapy may also predict the subsequent course. In a small series of 48 patients, $58 \%$ of antibody-negative patients were in persistent remission after 5 years compared with none of antibodypositive patients [30]. However, further prospective studies on large cohorts of patients are needed before drawing definitive conclusions. They will also enable the establishment of the meaning and therapeutic implication of the persistence of $\mathrm{PLA}_{2} \mathrm{R}$ antigen in immune deposits in repeat biopsies.

Anti-PLA ${ }_{2} \mathrm{R}$ antibodies should be regularly assessed in patients who have received a kidney graft from the time of transplantation. $\mathrm{MN}$ is one of the most frequent etiologies of nephrotic syndrome after renal transplantation. Recurrence of MN, which occurs in $10-40 \%$ of cases, can result in graft loss. A few reports have described very early recurrence of $\mathrm{PLA}_{2} \mathrm{R}$-related $\mathrm{MN}$, and all such cases were associated with anti-PLA ${ }_{2} \mathrm{R}$ antibodies [17-20]. Patients with detectable circulating anti-PLA ${ }_{2} \mathrm{R}$ antibodies prior to transplantation might be predisposed to recurrence although not all patients with high titers of antibody will recur [19]. It was recently shown that the titer of IgG4 anti-PLA ${ }_{2} \mathrm{R}$ during follow-up could predict $\mathrm{MN}$ recurrence [31]. Because $50-83 \%$ of recurrent cases of $M N$ are associated with anti-PLA ${ }_{2} \mathrm{R}$ antibodies, removing these antibodies before transplantation could be a promising therapeutic approach. Search for anti-PLA ${ }_{2} \mathrm{R}$ antibodies in blood and $\mathrm{PLA}_{2} \mathrm{R}$ antigen in kidney biopsy specimen was almost always negative in de novo $\mathrm{MN}$, suggesting a different pathophysiological mechanism most likely related to alloimmunization.

\section{Conclusion}

The recent breakthroughs in the pathomechanisms of $\mathrm{MN}$ have induced a paradigm shift in the diagnosis and monitoring of patients with this disease. Numerous uncertainties still remain as to the genetic and environmental triggering events, the mechanisms of complement activation, and the epitope(s) recognized. However, the spectrum of human MN now needs to be revisited according to the newly identified antigen-antibody systems, which should be considered as molecular signatures of the disease. These signatures, particularly the new tools of $\mathrm{PLA}_{2} \mathrm{R}$ serology, offer great promise for a new personalized medical approach which should be taken into account in future clinical practice guidelines.

\section{Disclosure Statement}

Roche provided the authors with rituximab for a RCT (Randomized Controlled Trial). 


\section{References}

-1 Heymann W, Hackel DB, Harwood S, Wilson SG, Hunter JL: Production of nephrotic syndrome in rats by Freund's adjuvants and rat kidney suspension. Proc Soc Exp Biol Med 1959; 100:660-664.

-2 Border WA, Ward HJ, Kamil ES, Cohen AH: Induction of membranous nephropathy in rabbits by administration of an exogenous cationic antigen. J Clin Invest 1982;69:451461.

3 Kerjaschki D, Farquhar MG: The pathogenic antigen of Heymann nephritis is a membrane glycoprotein of the renal proximal tubule brush border. Proc Natl Acad Sci 1982;79: 5557-5561.

4 Debiec H, Guigonis V, Mougenot B, Decobert F, Haymann JP, Bensman A, Deschênes G, Ronco PM: Antenatal membranous glomerulonephritis due to anti-neutral endopeptidase antibodies. N Engl J Med 2002;346:20532060.

$>5$ Debiec H, Nauta J, Coulet F, van der Burg M, Guigonis V, Schurmans T, de Heer E, Soubrier F, Janssen F, Ronco P: Role of truncating mutations in MME gene in feto-maternal allo-immunization and neonatal glomerulopathies. Lancet 2004;364:1252-1259.

6 Beck LH Jr, Bonegio RG, Lambeau G, Beck DM, Powell DW, Cummins TD, Klein JB, Salant DJ: M-type phospholipase $\mathrm{A}_{2}$ receptor as target antigen in idiopathic membranous nephropathy. N Engl J Med 2009;361:11-21.

7 Stanescu HC, Arcos-Burgos M, Medlar A, Bockenhauer D, Kottgen A, Dragomirescu L, Voinescu C, Patel N, Pearce K, Hubank M, Stephens HA, Laundy V, Padmanabhan S, Zawadzka A, Hofstra JM, Coenen MJ, den Heijer M, Kiemeney LA, Bacq-Daian D, Stengel B, Powis SH, Brenchley P, Feehally J, Rees AJ, Debiec H, Wetzels JF, Ronco P, Mathieson PW, Kleta R: Risk HLA-DQA1 and PLA(2)R1 alleles in idiopathic membranous nephropathy. N Engl J Med 2011;364:616-626.

$>8$ Debiec H, Lefeu F, Kemper M, Niaudet P, Deschênes G, Remuzzi G, Ulinski T, Ronco P: Early childhood membranous nephropathy due to cationic bovine serum albumin. N Engl J Med 2011;364:2101-2110.

$>9$ Debiec H, Ronco P: PLA 2 R autoantibodies and $\mathrm{PLA}_{2} \mathrm{R}$ glomerular deposits in membranous nephropathy. N Engl J Med 2011;364: 689-690.

10 Hoxha E, Kneißler U, Stege G, Zahner G, Thiele I, Panzer U, Harendza S, Helmchen UM, Stahl RA: Enhanced expression of the Mtype phospholipase $\mathrm{A}_{2}$ receptor in glomeruli correlates with serum receptor antibodies in primary membranous nephropathy. Kidney Int 2012;82:797-804.
11 East L, Isacke CM: The mannose receptor family. Biochim Biophys Acta 2002;1572: 364-386.

12 Llorca O: Extended and bent conformations of the mannose receptor family. Cell Mol Life Sci 2008;65:1302-1310.

13 Behnert A, Fritzler MJ, Teng B, Zhang M, Bollig F, Haller $\mathrm{H}$, Skoberne A, Mahler M, Schiffer M: An anti-phospholipase $\mathrm{A}_{2}$ receptor quantitative immunoassay and epitope analysis in membranous nephropathy reveals different antigenic domains of the receptor. PLoS One 2013,8:e61669.

14 Debiec H, Ronco P: Immunopathogenesis of membranous nephropathy: an update. Semin Immunopathol 2014;4:381-397.

15 Lv J, Hou W, Zhou X, Liu G, Zhou F, Zhao N, Hou $\mathrm{P}$, Zhao $\mathrm{M}$, Zhang $\mathrm{H}$ : Interaction between $\mathrm{PLA}_{2} \mathrm{R} 1$ and HLA-DQA1 variants associates with anti-PLA ${ }_{2} \mathrm{R}$ antibodies and membranous nephropathy. J Am Soc Nephrol 2013;24:1323-1329.

16 Coenen MJ, Hostra JM, Debiec H, Stanescu HC, Medlar A, Stengel B, Groothuismink JM, Bockenhauer D, Powis SH, Mathieson PW, Brenchley PE, Kleta R, Wetzels JF, Ronco P: Phospholipase $\mathrm{A}_{2}$ receptor $\left(\mathrm{PLA}_{2} \mathrm{R} 1\right)$ sequence variants in idiopathic membranous nephropathy. J Am Soc Nephrol 2013;24: 677-683.

17 Stahl R, Hoxha E, Fechner K: $\mathrm{PLA}_{2} \mathrm{R}$ autoantibodies and recurrent membranous nephropathy after transplantation. N Engl J Med 2010;363:496-498.

18 Blosser CD, Ayalon R, Nair R, Thomas C, Beck LH Jr: Very early recurrence of antiPhospholipase $\mathrm{A}_{2}$ receptor-positive membranous nephropathy after transplantation. Am J Transplant 2012;12:1637-1642.

19 Debiec H, Martin L, Jouanneau C, Dautin G, Mesnard L, Rondeau E, Mousson C, Ronco P: Autoantibodies specific for the phospholipase A2 receptor in recurrent and de novo membranous nephropathy. Am J Transplant 2011; 11:2144-2152.

20 Debiec H, Hanoy M, François A, Guerrot D, Ferlicot S, Johanet C, Aucouturier P, Godin M, Ronco P: Recurrent membranous nephropathy in an allograft caused by IgG $3 \kappa$ targeting the $\mathrm{PLA}_{2}$ receptor. J Am Soc Nephrol 2012;23:1949-1954.

-21 Knehtl M, Debiec H, Kamgang P, Callard P, Cadranel J, Ronco P, Boffa JJ: A case of phospholipase $\mathrm{A}_{2}$ receptor-positive membranous nephropathy preceding sarcoid-associated granulomatous tubulointerstitial nephritis. Am J Kidney Dis 2011;57:140-143.
22 Larsen CP, Messias NC, Silva FG, Messias E, Walker PD: Determination of primary versus secondary membranous glomerulopathy utilizing phospholipase $\mathrm{A}_{2}$ receptor staining in renal biopsies. Mod Pathol 2013;26:709-715.

-23 Svobodova B, Honsova E, Ronco P, Tesar V, Debiec H: Kidney biopsy is a sensitive tool for retrospective diagnosis of $\mathrm{PLA}_{2} \mathrm{R}$-related membranous nephropathy. Nephrol Dial Transplant 2013;28:1839-1844.

24 Qu Z, Liu G, Li J, Wu LH, Tan Y, Zheng X, Ao J, Zhao MH: Absence of glomerular IgG4 deposition in patients with membranous nephropathy may indicate malignancy. Nephrol Dial Transplant 2012;27:1931-1937.

-25 Beck LH Jr, Fervenza FC, Beck DM, Bonegio RG, Malik FA, Erickson SB, Cosio FG, Cattran DC, Salant DJ: Rituximab-induced depletion of anti-PLA 2 R autoantibodies predicts response in membranous nephropathy. J Am Soc Nephrol 2011;22:1543-1550.

26 Hofstra JM, Debiec H, Short CD, Pellé T, Kleta R, Mathieson PW, Ronco P, Brenchley PE, Wetzels JF: Antiphospholipase $\mathrm{A}_{2}$ receptor antibody titer and subclass in idiopathic membranous nephropathy. J Am Soc Nephrol 2012;23:1735-1743.

27 Oh YJ, Yang SH, Kim DK, Kang SW, Kim YS: Autoantibodies against phospholipase $\mathrm{A}_{2}$ receptor in Korean patients with membranous nephropathy. PLoS One 2013;8:e62151.

28 Hoxha E, Thiele I, Zahner G, Panzer U, Harendza S, Stahl RA: Phospholipase $\mathrm{A}_{2}$ receptor autoantibodies and clinical outcome in patients with primary membranous nephropathy. J Am Soc Nephrol 2014;25:1357-1366.

29 Kanigicherla D, Gummadova J, McKenzie EA, Roberts SA, Harris S, Nikam M, Poulton K, McWilliam L, Short CD, Venning M, Brenchley PE: Anti-PLA ${ }_{2} \mathrm{R}$ antibodies measured by ELISA predict long-term outcome in a prevalent population of patients with idiopathic membranous nephropathy. Kidney Int 2013;83:940-948.

30 Bech AP, Hofstra JM, Brenchley PE, Wetzels JF: Association of anti-PLA 2 R antibodies with outcomes after immunosuppressive therapy in idiopathic membranous nephropathy. Clin J Am Soc Nephrol 2014;9:1386-1392.

31 Seitz-Polski B, Payré C, Ambrosetti D, Albano L, Cassuto-Viguier E, Berguignat M, Jeribi A, Thouret MC, Bernard G, Benzaken S, Lambeau G, Esnault VL: Prediction of membranous nephropathy recurrence after transplantation by monitoring of anti-PLA 2 R1 (M-type phospholipase $\mathrm{A}_{2}$ receptor) autoantibodies: a case series of 15 patients. Nephrol Dial Transplant 2014, Epub ahead of print. 